\title{
Regular Article \\ Spectrophotometric Method Development andValidation for Estimation of Ibuprofen and Famotidine in the pharmaceutical formulation
}

\author{
Patel Rajeshri Dineshbhai *, Shukla Riddhi Hiteshbhai, \\ Buch Prakruti Rajeshbhai
}

Department of Pharmaceutical Sciences, Saurashtra University, Rajkot-5

*Corresponding author Email ID : rajeshripatel.2504@gmail.com

Ibuprofen is a nonsteroidal anti-inflammatory agent (NSAIA) with analgesic and antipyretic properties. Famotidine is a competitive histamine $\mathrm{H} 2-$ receptor antagonist, is used to treat gastrointestinal disorders such as gastric or duodenal ulcer. The aim of the present research work was to develop accurate and rapid Area under Curve Method to determine Ibuprofen and Famotidine in combined dosage form. The Area under Curve method, wavelength range selected are 259-269 $\mathrm{nm}$ for Ibuprofen and 282-292 $\mathrm{nm}$ for Famotidine respectively. The developed method was obeyed the Beer's law and was found linearity range between $80-640 \mu \mathrm{g} / \mathrm{ml}$ for IBU and 2-22 $\mu \mathrm{g} / \mathrm{ml}$ for Famotidine; while the correlation coefficient were 0.9985 for Ibuprofen and 0.9982 for Famotidine. Parameters such as linearity, accuracy, precision, LOD and LOQ values were used for validation of the methods as per ICH guidelines for both methods. Intra and inter-day precision \%RSD values were less than $2 \%$. This method is found suitable for day to day analysis of Ibuprofen and Famotidine in combined dosage form.

Keywords: Ibuprofen (IBU), Famotidine (FAM), Area under curve (AUC), UV Spectrophotometer, Rheumatoid arthritis (RA), nonsteroidal anti-inflammatory disease (NSAID)

Rheumatoid arthritis (RA) is an autoimmune disease that causes chronic inflammation of the joints which cause inflammation of the tissue around the joints, as well as in other organs in the body (Majithia and Geraci, 2007). A multi-center study of a national survey published in Arthritis Care and Research, a journal of the American College of Rheumatology, has established that over half of women with RA have fewer children than desired (Petra, 2012). Horizon Pharma,
Inc., a biopharmaceutical company developing and commercializing innovative medicines to target arthritis, pain and inflammatory diseases, announced that the U.S. Food and Drug Administration (FDA) has approved DUEXIS® fixed-dose tablet formulation of the NSAID IBU (800 $\mathbf{~ m g}$ ) and the histamine-H2 receptor blocker FAM 26.6 mg (FDA, 2011 and IP, 2010). Based on the literature review, it is found that number of studies involving methods development for estimation of IBU and 
FAM have been carried out in formulations/biological fluid with single or combination with other drugs. Thus, number of analytical methods including RP-HPLC (Safila, et al.,2011), LC-MS (Gros, et al.,2006), GC-MS (Farré, et al.,2007), spectroflourimetry, UVspectrometry (Ashiru, et al., 2007), Capillary Electrophoresis (Hamoudová and Pospíšilová, 2006) have been developed but there was no mention of the AUC method based on UVSpectrophotometric for determination of IBU and FAM in combined dosage form. AUC method based on selection of the wavelength range; where drug shows maximum absorbance. So in this study simple, rapid, precise, and accurate spectrophotometric method has been developed for the determination of IBU and FAM in combined dosage form and validated as per the ICH guideline.

\section{Materials and Methods}

\section{Reagents and Materials}

Active Pharmaceutical Ingredient (API) of IBU and FAM supplied by Zydus Cadila Health Care Ltd. Ahmedabad. The pharmaceutical dosage form used in study was DUEXIS®(label claim, IBU $800 \mathrm{mg}$ and FAM 26.6mg) manufactured by (Horizon Pharma, Inc., IL).Methanol AR grade was purchased from (Finar Chemicals Pvt. Ltd, Ahmedabad, India).

\section{Instrumentation}

UV-Visible double beam spectrophotometer (SHIMADZU 1700) with $10 \mathrm{~mm}$ matched quartz cells was used. All weighing were done on precision balance (REPTECH), and Ultrasonicsteri-cleaner was used (CYBERLAB) to degas the solutions.

\section{Selection of common solvent}

Based on drug profile, the solubility of both drugs was in Methanol. So Methanol was selected as the common solvent.

Preparation of Standard stock solution $80 \mathrm{mg}$ of IBU and $26.6 \mathrm{mg}$ of FAM of standard API were weighed and transferred in $100 \mathrm{ml}$ volumetric flask, dissolved and diluted up to the mark with Methanol to get final concentration $800 \mu \mathrm{g} / \mathrm{ml}$ of IBU and $266 \mu \mathrm{g} / \mathrm{ml}$ of FAM. FAM solution then further diluted to get concentration was 26.6 $\mu \mathrm{g} / \mathrm{ml}$ and both concentrations were as per label claimed (1:30.07).

\section{Preparation of Sample solution(Tablet)}

Amount of the powdered tablets equivalent to $80 \mathrm{mg}$ IBU and $2.66 \mathrm{mg}$ FAM was weighed and dissolved with Methanol to $100 \mathrm{ml}$ volumetric flask. The mixture was mixed and sonicated for $10 \mathrm{~min}$ and made up to the mark, to get final concentration $800 \mu \mathrm{g} / \mathrm{ml}$ and $26.6 \mu \mathrm{g} / \mathrm{ml}$ of IBU and FAM respectively. After that filter with whatmann filter paper (No.41) to remove unwanted particle. The filtrate was used as Sample solution.

\section{Development of the Area Under Curve (AUC) Method}

Selection of analytical wavelength range

The standard stock solutions were scanned in between the wavelength range 200-400 nm. From spectra of drugs, AUC of IBU and FAM were selected at 259-269 $\mathrm{nm}$ and at 282-292 $\mathrm{nm}$ for the analysis (Figure 1 and 2 respectively) was selected for the analysis. The calibration curve was prepared in the concentration range of 
$80-640 \mu \mathrm{g} / \mathrm{ml}$ for IBU and $2-22 \mu \mathrm{g} / \mathrm{ml}$ for FAM at their respective AUC range. By using the calibration curve, the

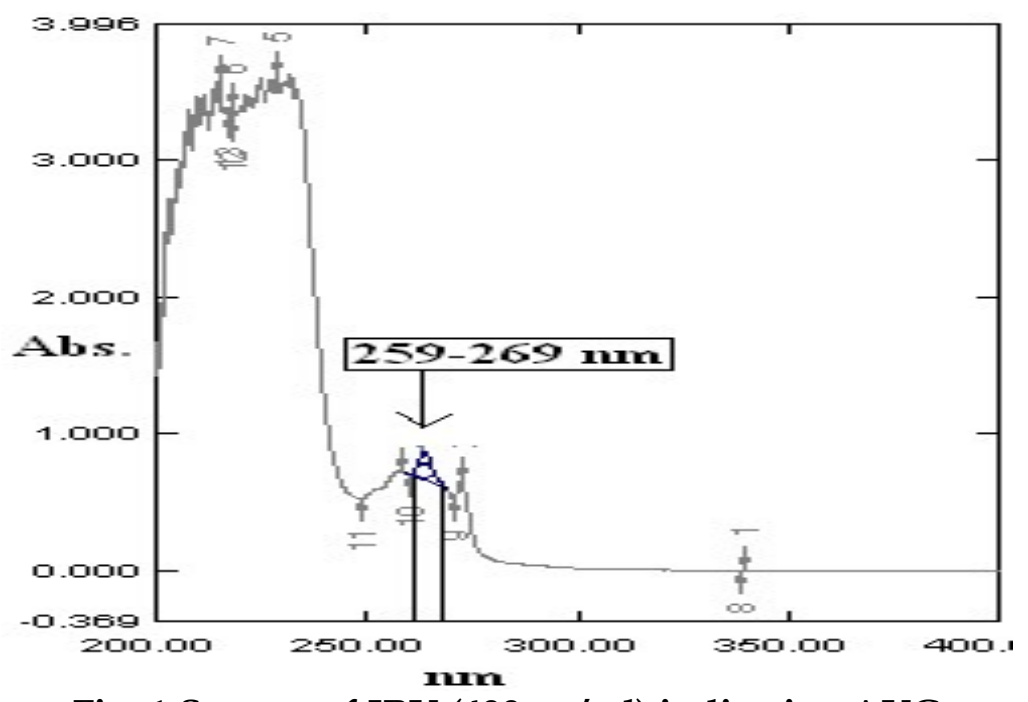

Fig. 1 Spectra of IBU $(400 \mu \mathrm{g} / \mathrm{ml})$ indicating AUC

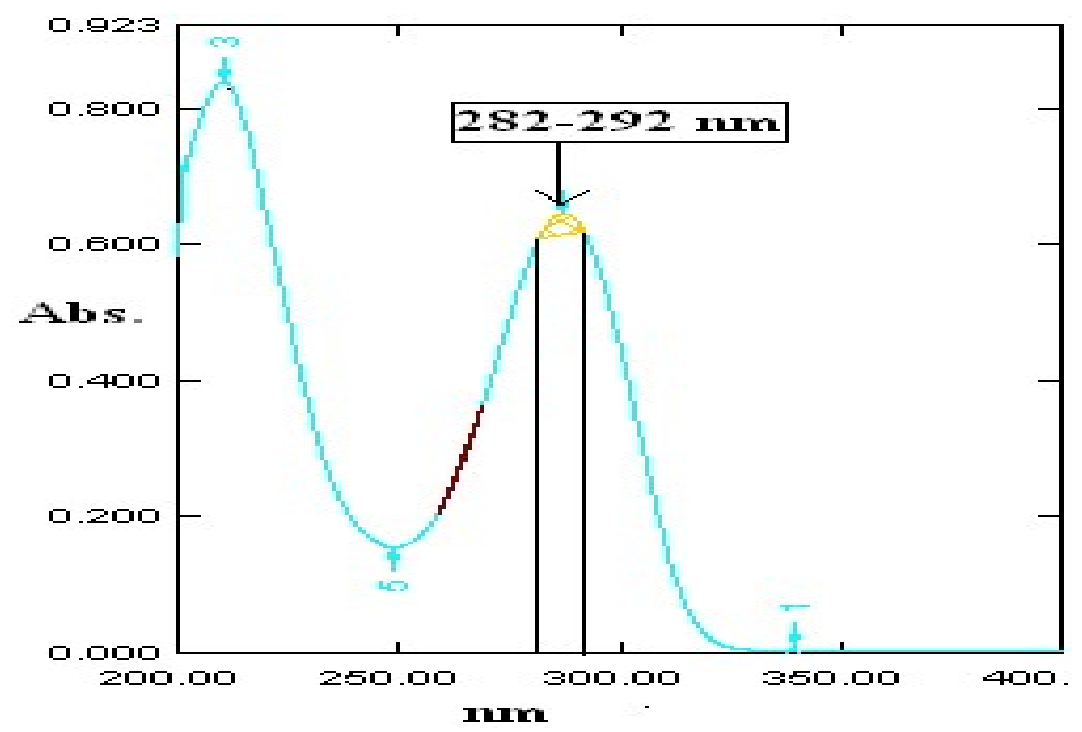

Fig. 2 Spectra of FAM $(13.3 \mu \mathrm{g} / \mathrm{ml})$ indicating AUC

\section{Validation Parameters}

The proposed method is validated according to the International Conference on Harmonization(ICH) guidelines.

\section{Linearity}

The linear response of was determined by analyzing six independent levels of concentration of the sample solution can be determined. 


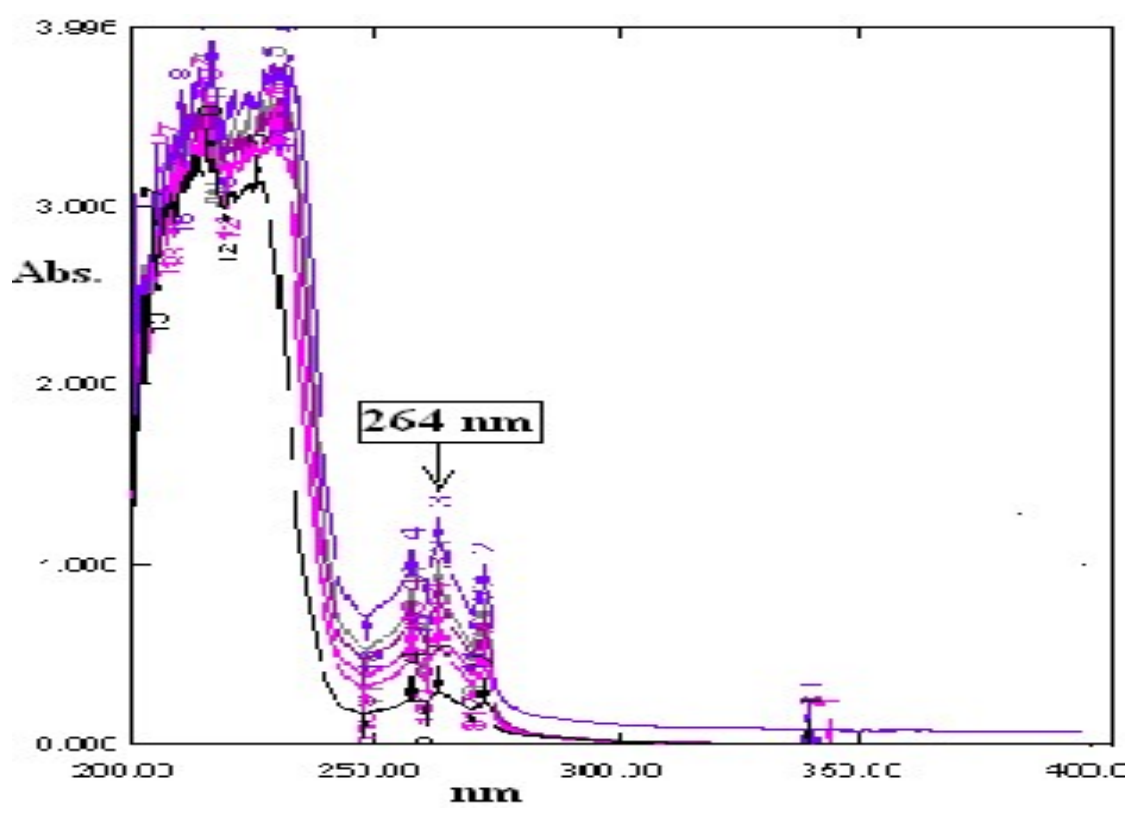

Fig. 3 Linearity curve for IBU at $264 \mathrm{~nm}$

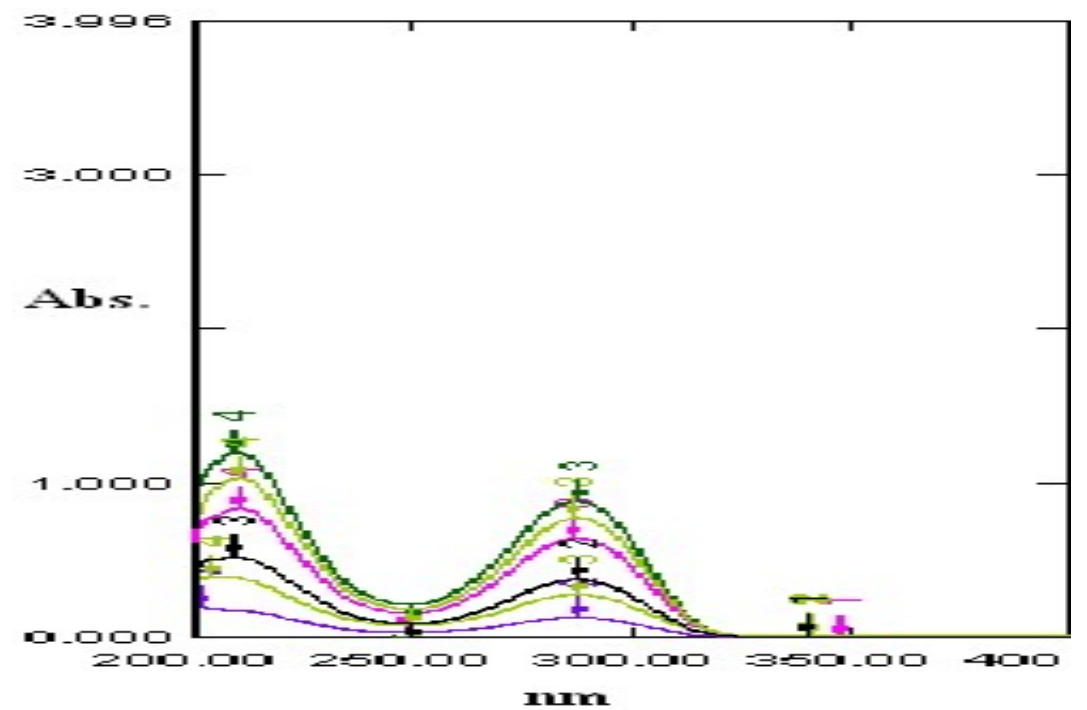

Fig. 4 Linearity curve for FAM at $287 \mathrm{~nm}$

Precision

Repeatability (Intra-assay Precision)

Repeatability was performed by preparing the sample (test) solution of IBU $(400 \mu \mathrm{g} / \mathrm{ml})$ and FAM $(13.3 \mu \mathrm{g} / \mathrm{ml})$ for six times and analyzed as per the proposed method. Percentage relative standard deviation (\%RSD) should be less than $2 \%$.

Intermediate Precision (Intra-day precision)

Variation of results within same day is called Intra-day precision. The Intraday precision was determined for standard solution of IBU $(400 \mu \mathrm{g} / \mathrm{ml})$ 
and FAM $(13.3 \mu \mathrm{g} / \mathrm{ml})$ for the three different time points for each six times on the same day.

\section{Reproducibility (Inter-day precision)}

It expresses within laboratory variations as on different days analysis or equipment within the laboratory. Variation of results amongst days called Inter-day precision. The Inter-day precision was determined for standard solution of IBU $(400 \mu \mathrm{g} / \mathrm{ml})$ and FAM $(13.3 \mu \mathrm{g} / \mathrm{ml})$ for three days.

\section{Accuracy (\% Recovery)}

Accuracy may often be expressed as \% Recovery by the assay of known, added amount of analyte. It's measure of the exactness of the analytical method. The recovery experiments were carried out in triplicate by sparking previously analyzed samples of the IBU (400 $\mu \mathrm{g} / \mathrm{ml})$ and FAM $(13.3 \mu \mathrm{g} / \mathrm{ml})$ with three different concentrations of standards at $80 \%, 100 \%$ and $120 \%$ respectively.

\section{Sensitivity}

Limit of detection (LOD) and limit of quantitation (LOQ) were calculated as $3.3 \sigma / S$ and $10 \sigma / S$ respectively; where $\sigma$ the standard deviation and $S$ is the slop.

Application of proposed Method to the pharmaceutical dosage form

The proposed validated method was successfully applied to determine IBU and FAM in the formulation. The concentration of each component was calculated by mathematical treatment of following mentioned equation.

For IBU, For FAM,

$$
C_{x}=A_{2} a_{1}-A_{1} a_{2} / a_{2} a y_{1}-a_{1} a_{2}
$$

$$
C_{y}=A_{1} a x_{2}-A_{2} a x_{1} / a x_{2} a y_{1}-a x_{1} a_{2}
$$

Where,

$\mathrm{C}_{\mathrm{x}}$ is the Concentration of IBU,

$\mathrm{C}_{\mathrm{y}}$ is the Concentration of FAM,

$\mathrm{A}_{1}$ is the Area of sample at $259-269 \mathrm{~nm}$,

$\mathrm{A}_{2}$ is the Area of sample at 282-292 nm, $\mathrm{ax}_{1}$ is the Absorptivity value of IBU at 259-269 nm, $\mathrm{ax}_{2}$ is the Absorptivity value of IBU at 282-292 nm, ay1 is the Absorptivity value of FAM at 259-269 nm, ay2 is the Absorptivity value of FAM at 282-292 $\mathrm{nm}$.

\section{Ruggedness}

Ruggedness of the proposed analytical method was determined by analyzing the same sample solution by two analysts and two different instruments using similar experimental condition. $\%$ RSD should be less than $5 \%$.

\section{Results and Discussion}

In this method the simple UV spectrum of IBU and FAM in methanol were obtained and area between two selected wavelengthsmeasuredi.e264 $\mathrm{nm}$ and $287 \mathrm{~nm}$ respectively (Figure 1 and 2). The calibration curve was linear in concentration range of $80-640 \mu \mathrm{g} / \mathrm{mL}$ and 2-22 $\mu \mathrm{g} / \mathrm{mL}$ respectively. The proposed method was found to be simple, sensitive, rapid, accurate, precise and economic for the routine analysis of IBU and FAM in combined pharmaceutical formulation. Accuracy was determined by calculating the recovery, and the mean was determined (Table 1,2). Precision was calculated as repeatability, intraday and intermediate variation in term of \% RSD for IBU and FAM. LOD values for IBU and FAM were found to be 9.57 and $0.22 \mu \mathrm{g} / \mathrm{ml}$ respectively and for LOQ values were found to be 29.00 and $0.65 \mu \mathrm{g} / \mathrm{ml}$ respectively indicates sensitivity of the 
proposed methods. The method was successfully used to determine the amounts of IBU and FAM present in tablets. The results obtained are in good agreement with the corresponding labelled amount (Table 3). Characteristic parameters and summary of validation parameters for both methods are given in Table 4. By observing the validation parameters, the method was found to be sensitive, accurate and precise. Hence the methods can be employed for the routine analysis of IBU and FAM in tablet formulations.

Table 1: Recovery Data for IBU

\begin{tabular}{|c|c|c|c|c|c|c|c|}
\hline & $\begin{array}{l}\text { Total } \\
\text { AUC }\end{array}$ & $\begin{array}{l}\text { Conc. } \\
\text { found }\end{array}$ & \%Recovery & $\begin{array}{c}\text { Avg. } \\
\text { \%Recovery }\end{array}$ & $\begin{array}{c}\text { Mean } \\
\text { AUC }\end{array}$ & SD & $\%$ RSD \\
\hline \multirow{3}{*}{$80 \%$} & 0.728 & 722 & 100.27 & \multirow{3}{*}{99.36} & \multirow{3}{*}{0.7213} & \multirow{3}{*}{0.0065} & \multirow{3}{*}{0.902} \\
\hline & 0.715 & 709 & 98.47 & & & & \\
\hline & 0.721 & 715 & $\begin{array}{l}99.30 \\
\end{array}$ & & & & \\
\hline \multirow{3}{*}{$100 \%$} & 0.813 & 807 & 100.87 & \multirow{3}{*}{99.75} & \multirow{3}{*}{0.804} & \multirow{3}{*}{0.0079} & \multirow{3}{*}{0.9872} \\
\hline & 0.801 & 795 & 99.37 & & & & \\
\hline & 0.798 & 792 & 99.00 & & & & \\
\hline \multirow{3}{*}{$120 \%$} & 0.874 & 868 & 98.63 & \multirow{3}{*}{99.43} & \multirow{3}{*}{0.881} & \multirow{3}{*}{0.0070} & \multirow{3}{*}{0.7945} \\
\hline & 0.888 & 882 & 100.22 & & & & \\
\hline & 0.881 & 875 & 99.43 & & & & \\
\hline
\end{tabular}

SD- standard deviation, RSD-relative standard deviation

Table 2: Recovery Data for FAM

\begin{tabular}{|c|c|c|c|c|c|c|c|}
\hline & $\begin{array}{l}\text { Total } \\
\text { AUC }\end{array}$ & $\begin{array}{l}\text { Conc. } \\
\text { found }\end{array}$ & $\%$ Recovery & $\begin{array}{c}\text { Avg. } \\
\text { \%Recovery }\end{array}$ & $\begin{array}{l}\text { Mean } \\
\text { AUC }\end{array}$ & SD & $\%$ RSD \\
\hline \multirow{3}{*}{$80 \%$} & 0.949 & 23.72 & 99.10 & \multirow{3}{*}{99.38} & \multirow{3}{*}{0.9517} & \multirow{3}{*}{0.0083} & \multirow{3}{*}{0.8749} \\
\hline & 0.945 & 23.62 & 98.68 & & & & \\
\hline & 0.961 & 24.02 & 100.35 & & & & \\
\hline \multirow{3}{*}{$100 \%$} & 1.065 & 26.62 & 100.09 & \multirow{3}{*}{99.53} & \multirow{3}{*}{1.059} & \multirow{3}{*}{0.0121} & \multirow{3}{*}{1.1487} \\
\hline & 1.045 & 26.12 & 98.21 & & & & \\
\hline & 1.067 & 26.67 & 100.28 & & & & \\
\hline \multirow{3}{*}{$120 \%$} & 1.171 & 29.27 & 100.05 & \multirow{3}{*}{99.48} & \multirow{3}{*}{1.1643} & \multirow{3}{*}{0.0084} & \multirow{3}{*}{0.8913} \\
\hline & 1.165 & 29.12 & 99.53 & & & & \\
\hline & 1.157 & 28.92 & 98.85 & & & & \\
\hline
\end{tabular}

SD- standard deviation, RSD-relative standard deviation

The proposed method provides a suitable and precise way for simultaneous analysis of IBU and FAM in a combination dosage form. These drugs are highly prescribed now days to treat arthritis. Previous reports of simultaneous estimation of IBU and FAM documented various analytical methods development such as HPTLC (Patel, et al., 2012), HPLC (Nyola and Jeyabalan, 2012), simultaneous and QRatio method (Kesur et al., 2012). 
However, till date there are no reports available of simultaneous estimation of both the drugs by AUC method. The results of the present validated method are in good agreement with their respective label claims (Table 3). Therefore, the present analytical method developed accurate and rapid AUC method to determine IBU and FAM in combined pharmaceutical formulation.

\section{Conclusion}

The proposed spectrophotometric method provide simple, specific, precise, accurate and reproducible quantitative analysis for determination of IBU and FAM in tablet dosage form. The method was validated as per ICH guidelines in terms of linearity, accuracy, precision, limits of detection (LOD) and quantification (LOQ) and ruggedness. The method can be used for routine analysis of IBU and FAM in combined dosage form.

Table 3: Results of Analysis of Tablet Formulation

\begin{tabular}{|c|c|c|c|}
\hline $\begin{array}{c}\text { Formulation } \\
\text { (DUEXIS®) }\end{array}$ & $\begin{array}{c}\text { Amt taken } \\
(\mu \mathrm{g} / \mathrm{ml})\end{array}$ & $\begin{array}{c}\text { Assay } \\
(\mu \mathrm{g} / \mathrm{ml})\end{array}$ & $\begin{array}{c}\text { \% Assay } \pm \text { SD } \\
(n=6)\end{array}$ \\
\hline IBU & 400 & 398.487 & 99.62 \\
\hline FAM & 13.3 & 13.197 & 99.23 \\
\hline
\end{tabular}

SD- standard deviation

Table 4: Regression Analysis Data and Summary of Validation Parameters for the Proposed Method

\begin{tabular}{|l|c|c|}
\hline Parameter & IBU & FAM \\
\hline Linearity range & $80-640 \mu \mathrm{g} / \mathrm{mL}$ & $2-22 \mu \mathrm{g} / \mathrm{mL}$ \\
\hline Linearity Equation & $\mathrm{Y}=0.001 \mathrm{x}+0.006$ & $\mathrm{Y}=0.040 \mathrm{x}+0.000$ \\
\hline Correlation coefficient $\mathbf{( r}^{2}$ ) & 0.9985 & 0.9982 \\
\hline Accuracy (n=3) & $99.36 \%-99.75 \%$ & $99.38 \%-99.53 \%$ \\
\hline $\begin{array}{l}\text { Repeatability } \\
\text { (Intra-Assay Precision) }\end{array}$ & 0.517 & 0.484 \\
\hline $\begin{array}{l}\text { Intermediate Precision } \\
\text { (Intra-day Precision) }\end{array}$ & 0.694 & 0.921 \\
\hline $\begin{array}{l}\text { Reproducibility } \\
\text { (Inter-day Precision) }\end{array}$ & 1.112 & 1.019 \\
\hline LOD & 9.57 & 0.22 \\
\hline LOQ & 29.00 & 0.65 \\
\hline
\end{tabular}

\section{Acknowledgement}

The authors are thankful to Department of Pharmaceutical Sciences, Saurashtra University, Rajkot for providing needed facility for this work. The authors are also thankful to Zydus Cadila Health
Care Ltd. Ahmedabad, India for providing the samples of IBU and FAM.

\section{References}

Ashiru DA, Patel R and Basit AW. 2007. Simple and universal HPLC-UV 
method to determine cimetidine, ranitidine, famotidine and nizatidine in urine: Application to the analysis of ranitidine and its metabolites in human volunteers. J. Chromatogr. B. 2: 235-240.

Farré M, Petrovic M and Barceló D. 2007. Recently developed GC/MS and LC/MS methods for determining NSAIDs in water samples. Anal. Bioanal. Chem. 387(4): 1203-1214.

Gros M, Petrović $M$ and Barceló D. 2006. Development of a multi-residue analytical methodology based on liquid chromatography-tandem mass spectrometry (LC-MS/MS) for screening and trace level determination of pharmaceuticals in surface and wastewaters. Talanta. 70(4): 678-690.

Hamoudová R and Pospíšilová M. 2006. Determination of ibuprofen and flurbiprofen in pharmaceuticals by capillary zone electrophoresis. J Pharm Biomed Anal. 41(4): 14631467.

ICH, Q2 (R1). 2005. Validation of Analytical Procedure: Text and Methodology, International Conference on Harmonization.

ICH, Q2A. 1994. Harmonised Tripartite Guideline, Test On Validation Of Analytical

Indian pharmacopoeia. 2010. vol-II. Government of India, Ministry of Health and Family Welfare, Ghaziabad: Indian Pharmacopoeial Commission : 1331, 1479.
Kesur BR, Saluknke VR, Magdum CS. 2012. Development and validation of uv spectrophotometric method for simultaneous estimation of ibuprofen and famotidine in bulk and formulated tablet dosage form. Int J Pharm Pharma Sci. 2012; 4(4):271274.

Majithia V and Geraci SA. 2007. Rheumatoid arthritis: diagnosis and management. Am J Med. 120 (11): 936-939.

Nyola N and Jeyabalan GS. 2012. Simultaneous estimation of ibuprofen and famotidine in pure and combination dosage form by RPHPLC. J Appl Pharm Sci. 2 (5):79.

Patel R, Tanna R, Thumar K. 2012. HPTLC method for simultaneous estimation of Ibuprofen and Famotidine from tablet dosage form. Inventi Rapid: Pharm Ana Qual Assur Issue. (3): 1-6.

Petra, R. 2012. Arthritis and Lupus Linked To Lower Birth Rates. Medical News Today.

Safila N, Najma S and Saeed AM. 2011. Simultaneous determination of Lisinopril and $\mathrm{H}_{2}$ antagonists in API, formulations and human serum by using two different HPLC systems. Medicinal Chem. Res. 10: 107-110.

U.S. Food and Drug Administration (FDA), 2011. file:///DrugUpdates ArticleTheRheumatologist.htm (Accessed on 25th January 2016). 